\title{
CONCUSSION IN PARA SPORT
}

\author{
James Kissick MD, CCFP (SEM), Dip Sport Med \\ Carleton University Sport Medicine Clinic \\ University of Ottawa Department of Family Medicine \\ Ottawa, Ontario, Canada \\ jameskissick@me.com
}

\begin{abstract}
Professor Nick Webborn MB BS FFSEM FACSM FISM MSc Dip Sports Med Centre for Sport and Exercise Science and Medicine (SESAME), School of Sport and Service Management, University of Brighton, East Sussex, United Kingdom nickwebborn@sportswise.org.uk
\end{abstract}

DISCLOSURE STATEMENT: The authors have no conflicts or funding sources to disclose.

SYNOPSIS: While Para athletes (the International Paralympic Committee's term for sportspeople with a disability) are exposed to a risk of concussion just like their able-bodied counterparts, there has been little research into the incidence of concussion in Para sport. Existing assessment and management guidelines and tools have been developed for the general sport population, but may not be appropriate for use in some Para athletes. This review examines what is currently known about concussion in Para sport, and identifies challenges and opportunities in moving knowledge on this topic forward.

KEY WORDS: Concussion; Para sport; Para athlete; Athletes with a disability, Injury KEY POINTS:

- Para athletes are exposed to concussion risk, particularly in speed, collision and contact sports

- There is little incidence data on concussion in Para athletes

- Current assessment guidelines and tools (e.g. SCAT5) are not applicable to some Para athlete populations

- The management of concussion in the Para athlete may need to be adapted depending on the athlete impairment and sport

- Risk reduction strategies, particularly education, must be implemented 
It is probably safe to say that there has been no sport medicine topic more "newsworthy" than concussion over the past decade. In addition to intense interest from athletes, parents, the media and others, concussion has been a very popular subject of research, which has grown exponentially over the years. However, for the Para athlete (the International Paralympic Committee's term for a sportsperson with a disability), concussion struggles to attract interest and attention (1) (2). For example, a search strategy developed to find articles regarding athletes and concussion retrieved over 6000 , while one that was developed for athletes with disabilities and concussion only returned 60 articles. Furthermore, the recent Fifth International Consensus Conference on Concussion in Sport featured 202 oral and written abstracts, but only 2 were specific to athletes with a disability. Despite this, participation in sport by Para athletes continues to grow, and these athletes are exposed to the risk of concussion in sports which involve speed, collision and contact. This review will examine what is currently known about concussion in Para sport, and how assessment, management and risk reduction in this group of athletes might differ from the general athletic population. Current and future challenges will be discussed, but more importantly, opportunities for further study will be identified.

\section{Incidence}

As described by Van Mechelen et al. in their 4-step injury prevention model (3), the first step in prevention is to determine the incidence and severity of any injury one is hoping to prevent. While there are a number of Para sports where one would 
anticipate a greater risk of concussion, there is very little incidence data. Table 1 gives an example of 'best estimate' risk assessment by IPC Medical Committee members for summer and winter Paralympic sports, based on their experience and the available data of concussion risk considering the impairment type, speed, collision potential, protective wear and risk rating. This table will need refinement as more data becomes available but is a useful starting point for field-of-play clinicians and event organisers to consider.

\section{Paralympic Games injury surveillance}

The International Paralympic Committee (IPC) has conducted injury surveillance studies at the winter Paralympic Games since 2002, and the summer Paralympic Games since 2012. A web-based injury and illness surveillance system (WEB-IISS, was introduced at the London 2012 Games to enter injury data and has been used at all subsequent summer and winter Games. However, questions specifically related to concussion were not added to the WEB-IISS until the 2016 Rio Summer Paralympics. In 2002, alpine skiing (now termed Para alpine) and ice sledge hockey (now termed Para ice hockey) had the highest risk of any musculoskeletal injury out of all sports contested at the winter Paralympic Games. One might expect a higher risk of concussion in both sports due to the speed and impact involved, but no head injuries were reported. (4). The 2006 Torino Games surveillance study was hampered by some methodological issues; still, it noted 2 head injuries (one in alpine skiing, one in nordic skiing) out of 39 recorded injuries, but there is no further information on the specific type of head injury (eg. Scalp laceration, 
contusion, facial fracture, concussion etc) (5) At the 2010 Vancouver Winter Paralympics, two out of 40 reported injuries in Para ice hockey, and three out of 42 reported injuries in Para alpine skiing (all standing skiers with visual or physical impairment) were to the head, but again, there was no further differentiation into injury type. Data on Nordic skiers indicated one concussion out of 26 reported injuries (6). The most recent Winter Games study was done at the 2014 Sochi Games. Out of 174 total reported injuries, 31 injuries to the head, face and neck were reported, accounting for $4.8 \%$ of athletes with an injury and an Incidence Rate (IR) of 4.7 injuries per 1000 athlete days (3.2- $6.795 \% \mathrm{CI})$. The authors noted that overall, there was a higher injury incidence at the Sochi winter Games than in the Sochi Winter Olympics or London 2012 Summer Paralympic Games (7)

While one might intuitively expect that the incidence of concussion would be higher in a Winter Games setting, with "speed sports" such as Para alpine and "collision sports" such as Para ice hockey, the Summer Games includes a number of contact sports such as wheelchair basketball, wheelchair rugby, judo, and visually impaired football (Football 5). In addition, in some Para sports, there is a risk of concussion even though the sport's able-bodied equivalent is not traditionally associated with this injury. While the risk of concussion in an Olympic track event is unreported, the risk of a crash in wheelchair track athletes resulting in head injury is not uncommon, with two documented concussions from crashes occurring at the last two Para athletics World Championships. (see Fig. 1) At the London 2012 Paralympic Games, $2.2 \%$ of reported injuries (14/633) were to the head and face, 
however there was no differentiation into injury type (8). The Rio 2016 Games' study was the first to include specific reporting questions on concussion, with team physicians from 78 of the 81 participating countries using the WEB-IISS. If an injury to the head, face or neck was noted, the physician then received specific questions regarding concussion. $1.6 \%$ of total injuries $(7 / 440)$ were to the head and face, and 8.4\% (37/440) to the neck, giving IRs of $0.1(0.1$ to $0.395 \% \mathrm{CI}$ ) and 0.7 (0.5 to 1.0 95\% CI) per 1000 athlete days respectively. However, despite this, no concussions were reported (9). Concussions cannot be diagnosed from the stands with certainty, however during Football 5 matches, the authors witnessed clear head to head contact followed by players holding their heads and exhibiting apparent balance issues. These incidents. were also observed on review of video footage from the matches and were certainly suspicious of concussion. Thus, while no concussions were reported via WEB-IISS, this may not mean that none occurred. This points to the importance of improving concussion education for players, coaches, officials and health care staff.

Concussions will again be specifically questioned in the injury surveillance survey at the 2018 PyeonChang Winter Games, and the pre-event team physician seminar will highlight this issue. The smaller nature of the Winter Games may make injury follow-up easier, potentially yielding more information.

Sport-specific studies

A) Football 5 
Football 5 refers to football (soccer) for players with visual impairment. Goalkeepers are sighted, and call out defensive strategy to 4 visually impaired players who wear eyeshades to ensure all have no vision. The ball has a bell within it, and players are required to call out "voy!' ("I go" in Spanish) as they approach the player with the ball. In addition to being visually impaired, which reduces their ability to brace for or block a blow to the head, players tend to play in more of an upright position than non-visually impaired players, potentially exposing them to a greater risk of head to head collision (10). (see Fig. 2) Webborn et al found a high incidence of head and face injuries in this sport at the London 2012 Games (13.6\% of total injuries), although this was in only 22 total injuries. Injury incidence in the total Games population, as noted previously, was only $2.2 \%$. The other Paralympic football type is CP football, or Football 7s, played by athletes with cerebral palsy. Players have full vision, and there is no heading of the ball allowed, which reduces the risk of head collision. Again, the number of total injuries was low, but only 1/17 total injuries was to the head and face (7.1\%).(10).

A preliminary analysis of the data from Rio (as yet unpublished) showed that 5/17 (29\%) injuries in competition were to the head and face, and, furthermore, Football 5 remained the sport with the highest rate of injury of all sports at the Games. Magno e Silva reported that head injuries made up $8.6 \%$ of all injuries to visually impaired international Brazilian footballers over 4 years (five competitions) (11).

B) Wheelchair basketball 
Wheelchair basketball is played by both men and women on a standard sized basketball court. It is fast-paced, and contact certainly occurs. Wessels et al. reported on a self-report survey of 263 athletes from age 18-60 playing in tournaments during the $2009-10$ season. $6.1 \%$ of players reported having had a concussion, similar to the reported incidence in able-bodied basketball. $44 \%$ did not report their symptoms to team staff; of these, $67 \%$ said it was because they did not want to be removed from play. $50 \%$ did not know they had a concussion at the time. Females had a 2.5 times higher concussion rate, but there were a limited number of females in the study (12). While some athletes use a wheelchair regularly, some have impairments that do not necessitate regular wheelchair use. Interestingly, this group had a higher rate of concussions than habitual wheelchair users. Wessels et al speculated that this finding reflects regular users having more experience and better balance in their chairs, or to the fact that some of the non-regular users were able to rise up in their chairs more, perhaps making them more unstable.

C) Para ice hockey

Like its "stand up" counterpart, Para ice hockey (formerly known as ice sledge hockey) is a fast game played on an ice surface surrounded by hard "boards." Body contact is part of the game and collisions, both intentional and unintentional, occur regularly. Accordingly, the risk for concussion would seem quite significant. However, there have been no published studies regarding concussion in this sport; the only relevant data comes from the Paralympic surveillance studies described above. Hawkeswood et al. surveyed team representatives (physician where the 
team had one, therapist, coach and manager) of the top-ranked Para ice hockey teams at the Vancouver 2010 Games. Concussions were a significant concern, with bodychecking felt to be the main mechanism of injury (13). While this was a small anecdotal study, it may indicate that concussions are under-reported as none were recorded in the 2010 Games survey, and thus more of a concern than surveillance studies have indicated thus far.

\section{Summary}

While concussion risk in Para sports seems intuitively and anecdotally significant, there is minimal data. Sport-specific incidence studies, using consistent injury definition and well designed methodology are needed; this is an excellent opportunity for researchers to provide valuable information and address this important first step in injury prevention.

\section{Assessment}

The Consensus Statement from the Fifth International Conference on Concussion in Sport states, "The recognition of suspected SRC (sport related concussion) is therefore best approached using multi-dimensional testing guided by expert consensus. The SCAT5 currently represents the most well-established and rigorously developed instrument for sideline assessment" (14). The SCAT5 and its predecessors have been widely used by clinicians throughout the world to guide their sideline assessment of concussion. As there is little published research on concussion assessment in Para athletes specifically, most clinicians working with 
these athletes will likely look to existing assessment tools for the general sport population like the SCAT5 for guidance. However, there are portions of the SCAT5 which are not appropriate or valid for use in the Para athlete, and will need to be modified. In an accompanying paper to the Consensus Statement regarding the SCAT5, it is noted that the systematic review performed for the development of this tool found there was "scant information on the use of the SCAT in athletes with disabilities, as well as across different cultures and language groups" (15). In addition, Para athletes do not represent a homogeneous population; there are a wide range of impairments, not only within Para sport as a whole, but also within individual Para sports. Thus, a "one size fits all" approach will not be possible. Table 2 looks at potential challenges to the use of the SCAT5 in the disabled population. The challenges noted are not an exhaustive list, and some, such as learning disability or hearing impairment, may also be present in the general sporting population. Cognitive testing may be similarly difficult in some cultures and languages. However, it serves as reminder that, as noted by the authors of the SCAT5, a systematic approach is needed to adapt the SCAT5 for use among athletes with disabilities, and across diverse cultures and language groups.

A growing body of normative data has been obtained over the years the SCAT has been used. However, is this applicable to the Para athlete population? Weiler et al. compared baseline SCAT3 scores in football (soccer) players with a disability and those without, and found significant differences. Male visually impaired (VI) players had higher scores for total concentration and delayed recall [reflecting better scores 
than the group without a disability) Male players with cerebral palsy (CP) scored higher on immediate memory and balance testing (which reflects a greater number of errors on balance tests). Female players with hearing impairment scored higher for total concentration and balance (again, greater number of errors) than female players without a disability (16).

While the Concussion in Sport group did not recommend baseline or post-injury neuropsychological (NP) testing as mandatory for all athletes (14), brief computerized NP tests are frequently used, particularly in more elite sport with a higher concussion risk. Use of these tools will not be possible in athletes with significant visual impairment, and may be difficult to use in athletes who have difficulty using a computer mouse or those with a cognitive impairment or learning disability.

As noted in Table 2, balance testing may pose a significant challenge. The modified Balance Error Scoring System (mBESS) will not be possible for athletes in a wheelchair. There is no data on its use for athletes with lower limb amputations wearing a prosthesis. As noted previously, Weiler et al. found increased balance errors in male $\mathrm{CP}$ footballers, and female footballers with a hearing impairment.

Wessels described a proposed "Wheelchair Error Scoring System", or WESS, which consisted of 6 tests to measure seated postural control: sitting on a hard surface, 
feet not touching the floor, hands on hips (eyes open and closed); sitting on a balance disc, feet not touching the floor (eyes open and closed); and holding a "wheelie" (front wheels off the ground) with eyes open and closed. While there was a small number of participants, good inter- and intra-tester reliability was found, and detected changes in postural control in each of the five cases of concussion during the study. The addition of a cognitive task increased postural control during the "wheelie" position; the author proposes this could be due to the participant's focus being diverted to the cognitive task, allowing balance to occur subconsciously, as it would normally. (17)

Knowledge of concussion assessment and assessment tools may be an issue in the Para sport world. West et al. commented on their experience at the 2015 CP Football World Cup, where physicians and physiotherapists working with teams were surveyed. While most reported some education in concussion assessment and management, as well as experience in managing a player with a concussion, several reported they relied more on subjective factors like their knowledge of their player. There was a low rate of use of the SCAT3, or any other assessment tool, and a rather high reliance on imaging (18). It was not identified why this might be; it may have been a lack of awareness of existing assessment tools, or perhaps the clinicians didn't find them helpful, given aforementioned challenges in their use among Para athletes. If the former, while it may not be generalizable to other Para sports, it does speak to the need for education for health care providers working with Para 
athletes. The latter reinforces the need to develop assessment tools which are applicable to Para athletes.

\section{Management}

To date, there are no published guidelines or clinical consensus statements specific to the management of concussion in the Para athlete. The experience of the authors, and of other experienced clinicians, is to adhere to the recommendations of the Concussion in Sport Group, who recommend removal of an athlete from game, practice or activity if a concussion is suspected, and, where a concussion is diagnosed, a brief period of rest followed by resumption of daily activities, then a graduated return to play protocol (14). However, as with assessment, there may be some challenges, or at least nuances, in the Para athlete, depending on their disability and sport. The functional consequences of concussion to a Para athlete can be greater than to an able bodied athlete (4). For example, a brief initial period of rest is recommended, and many with a concussion find that physical (and cognitive) exertion worsens their symptoms early on. Rest may be more difficult for the wheelchair user who must wheel, transfer, and utilize other forms of physical exertion during regular activities of daily living, particularly if they live on their own.

Other questions arise: computerized NP testing is often used to assess cognitive recovery and clearance for resumption of contact activity. As noted in the "Assessment" section, the use of this tool may be limited in some athletes. In 
addition, is it valid where certain impairments exist? Does the 6-step return to play strategy need to be made more gradual or altered for some athletes? For example, the Para ice hockey player will have to look down more at the puck when resuming non-contact drills than his/her "stand up" counterpart - this could potentially cause more dizziness and neck discomfort if introduced too early.

West et al.'s CP Football World Cup study identified that a number of clinicians were returning concussed athletes to play faster than recommended by the Concussion in Sport Consensus recommendations (at that point, the Zurich 2012 consensus). Several reported they were unaware of the existence of any concussion management guidelines (18). It is critical that clinicians providing care for Para athletes are aware of existing guidelines and recommendations.

\section{Risk Reduction}

It is clear that we are still at step 1 of the Van Mechelen model in "establishing the extent of the injury" (3), in relation to concussion incidence in Para sport. However, risk reduction strategies can and should be developed using existing principles of risk reduction but with specific consideration of the Para athlete's impairment and the specific sport. The athlete's impairment may increase collision risk; the example of the Football 5 athlete with visual impairment was previously described.

Strategies must also address the specifics of the sport, including potential for collision, impact velocity, whether head protection is used and what type, and sport rules. As noted by Caroline Finch, "To prevent injuries, sports injury prevention 
measures need to be acceptable, adopted and complied with by the athletes and sports bodies they are targeted at. If the athletes, coaches or sports administrators we are trying to work with will not use or adopt any of the prevention measures that we advocate, then all of our preventive efforts will fail (19)."

Renowned injury epidemiologist Susan Baker described the "3 E’s of Injury Prevention" in 1973: education, enforcement, and engineering (or environment). While these originally arose from her work in motor vehicle accident prevention, they have been widely adapted for injury prevention in general, including in sport, and provide a very useful framework for risk reduction strategies in Para sport (20).

\section{Education}

Effective education, or knowledge translation, is the most critical component of injury prevention; without appropriate knowledge and understanding of the injury one wishes to prevent, it is unlikely there will be good uptake of other strategies such as safer play, protective equipment use or adherence to rules. Wessel's et al.'s wheelchair basketball study found that $50 \%$ of those who had a concussion did not report it at the time since they did not know it was a concussion, and $42 \%$ thought it was just "part of the game. (17). The authors' experience in working with Para athletes also suggests that some may not consider concussion to be a significant issue for them, given previous illness or injury, such as cancer or severe trauma: “Thanks for the information, doc, but I'm not really worried about a bump to my head when I have been through far worse." Many Para athletes may be "risk takers"; 
for some, this may have been a contributing factor to a traumatic injury leading to an impairment. This behaviour may not have changed afterward, making potentially higher risk sports more attractive. Educational strategies must therefore emphasize that, despite their past experiences, it is still critically important to protect the brain.

Educational initiatives must be directed at multiple levels - not only athletes, but also health care providers, coaches, officials, sport administrators, and, in the case of younger athletes, parents. As previously noted, there seems to be a need to educate health care providers regarding concussion recognition, assessment and management. The most effective method for knowledge translation must be considered, and this may differ for each group. West et al. noted that clinicians would prefer to receive concussion education through courses or on-line materials (18). Athletes may prefer to receive information through social media. In addition to providing information about concussion, educational interventions can also include advice or instructions about safe play techniques, equipment use and the importance of rules designed to reduce injury risk.

\section{Enforcement}

In sport, this refers to the "rules" or "laws" of the game, which are put in place to ensure fair competition, and to protect athletes from injury. It is therefore important that all involved, including athletes, coaches and officials, understand and support these rules, not just when they are called against an opponent. Research in able bodied ice hockey has clearly demonstrated that hits to the head are associated with 
increased risk of concussion. This resulted in the "no head checking" rule, which is also used in Para ice hockey. Referees can enforce a more stringent penalty, including ejection from the game, and possible suspension from future games, if a players hits another player on the head. This is designed to act as a deterrent, as it could have a significant impact on both the player and his or her team. In Football 5, the "voy" rule requires that a player approaching the player in possession of the ball call out "voy". Strict enforcement of this rule is likely to reduce the frequency and severity of impacts, as the possessor of the ball should be more aware of a potential impact and take measures to try to avoid or protect.

\section{Engineering}

Engineering refers to the sport and athlete "environment", which includes the venue, field of play and equipment. The problem of player collisions in Football 5 has been previously described. Players are often in an upright position as they compete for the ball, and their lack of vision makes anticipation of the collision difficult - it is difficult to try to avoid the collision, or to "brace" by assuming a more protected position or by "pre-tensioning" muscles. (21) Players are required to wear eyeshades to ensure equal lack of vision, and, while acknowledging that no head protection in general use thus far can prevent concussion or reduce rotational forces to the brain, it was postulated that a combined eyeshade with head protection might confer a protective benefit in the head to head collisions seen in this sport. Examples are shown in Figure 3. The majority of research into protective headgear has taken place in high impact sports such as NFL Football and rugby union, neither 
of which is directly comparable to Football 5. The results of the London 2012 study opened up the opportunity to approach the international federation (IBSA Football) to consider this option and met with a favourable response. Consequently pilot work is being undertaken using a wearable sensor system to measure linear acceleration, and then through various algorithms also estimate angular acceleration. This will be attached to the mandatory eyeshade of the players. When combined with the clinical data following head collisions and its consequences, it may then be possible to design protective equipment that can defend against the measured forces.

The advent of new materials to reduce force impact has raised the possibility of more easily customizable sport specific wear. Already in use in industry and the military, products made from materials that are rate-sensitive, soft and flexible but with high shock absorbing properties are being increasingly used in protective sports products.(22) As the cost reduces it will become more affordable to become mandatory in sports if risk reduction benefit can be shown. However, as noted by Finch, "Sports bodies will not implement sports safety policies until they are sure that the safety measures actually prevent injuries, are acceptable to their participants, do not change the essential nature or appeal of the sport, and do not adversely affect participation or performance (19)."

The high rate of injury in Para alpine skiing at the Sochi Winter Paralympics also raises the issue of the safety of the "field of play". During the Games, temperatures 
during competition reached 18C, and did not often fall below 0C at night. The warm climate may have substantially contributed to poor snow conditions, potentially putting athletes at higher risk of injury (7).

\section{"Mind The Gap"}

Passengers on London's Underground are reminded to "Mind the Gap" to help ensure their safety in boarding and disembarking trains. This can also be an important direction to clinicians and researchers regarding the current state of knowledge about concussion in Para athletes. While ever-increasing study into concussion in the able bodied population has provided information that can be applied to the Para athlete, there is a significant gap in our knowledge about the specifics and nuances of concussion in this group. Recent editorials have emphasized the importance of addressing this issue (1) (23), however this gap presents a valuable opportunity for clinically-relevant research. Incidence data, mechanisms of injury, specific assessment and assessment tools, appropriate management and return to play, and risk reduction strategies are all are fertile ground for study, and will play an important role in helping Para athletes compete safely. While not the "final frontier," it is hoped that concussion in Para sport will be the "next frontier," including being a subject at the next International Conference on Concussion in Sport. As Star Trek’s Captain James T. Kirk said, “...there is no such thing as the unknown, only things temporarily hidden and not understood." (24) For the health and safety of Para athletes, and all those with a disability, it is imperative 
that the concussion knowledge gap be addressed.

\section{References:}

(1) Webborn N, Blauwet C, Derman W, Idrisova G, Lexell J, Stomphorst J, TuakliWorsonu Y, Kissick J. Heads up on concussion in para sport. Br J Sports Med 2017. doi:10.1136/ bjsports-2016-097236 . Accessed Jul 24, 2017

(2) Blauwet C, Lexell J, Derman W, Idrisova G, Kissick J, Stomphorst J, Tuakli Wosornu Y, Van de Vliet P, Webborn N. The Road To Rio: Medical and Scientific Perspectives on the 2016 Paralympic Games. J PM R 2016 (8): 798-801

(3) Van Mechelen W, Hlobil H, Kemper HC. Incidence, severity, aetiology and prevention of sports injuries. A review of concepts. Sports Med 1992 Aug 14(2): $82-89$

(4) Webborn, N., Willick S, Reeser J. Injuries among Disabled Athletes during the 2002 Winter Paralympic Games. Med Sci.Sports Exerc. 2006; 38(5): 811-815.

(5) Webborn AD. IPC Injury Survey Torino 2006. The Paralympian 2007: 2-11

(6) Webborn N, Willick S, Emery CA. The injury experience at the 2010 winter paralympic games. Clin J Sport Med 2012: 22: 3-9.

(7) Derman W, Schwellnus M, Jordaan E, Runciman P, Van dr Vliet P, Blauwet C, Webborn N, Willick S, Stomphorst j. High incidence of injury at the Sochi 2014 Winter Paralympic Games: a prospective cohort study of 6564 athlete days. Br J Sports Med 2016; 50: 1069-1074 
(8) Willick SE, Webborn N, Emery C, Blauwet CA, Pit-Grosheide P, Stomphorst J, Van de Vliet P, Patino M arques N A, M artinez-Ferrer JO, Jordaan E, Derman W, Schwellnus M. The epidemiology of injuries at the London 2012 Paralympic Games. Br J Sports Med 2013: 47: 426-432.

(9) Pre-competition injuries are significantly higher than competition injuries at the Rio 2016 Summer Paralympic Games: A prospective epidemiological study of 51,198 athlete days (In Review)

(10) Webborn N, Cushman D, Blauwet C, Emery C, Derman D, Schwellnus M, Stomphorst J, Van de Vliet P, Willick s. The Epidemiology of Injuries in Football at the London 2012 Paralympic Games. PM \& R 2016; 8(6): 542-552

(11) Magno e Silva MP, Morato MP, Bilzon JL, Duarte E. Sports injuries in brazilian blind footballers. Int J Sports Med 2013b: 34: 239-243.

(12) Wessels K, Broglio S, Sosnoff J. Concussions in Wheelchair Basketball. Arch Phys Med Rehabil 2012; 93: 275-278

(13) Hawkeswood J, Finlayson H, O'Connor R, Anton H. A Pilot Survey on Injury and Safety Concerns in International Sledge Hockey. Int J Sports Phys Ther. 2011; 6(3): 173-185

(14) McCrory P, Meeuwisse W, Dvorak J, Aubry M et al. Consensus Statement On Concussion In Sport - The $5^{\text {th }}$ International Conference On Concussion In Sport Held In Berlin, October 2016. Br J Sport Med 2017; 51: 838-847. 
(15) Echemendia R, Meeuwisse W, McCrory P, Davis G et al. The Sport

Concussion Assessment Tool fifth edition (SCAT5). Br J Sport Med 2017; 51: 848850.

(16) Weiler R, van Mechelen W, Fuller C, Ahmed O, Verhagen E. Do Neurocognitive SCAT3 Baseline Test Scores Differ Between Footballers (Soccer) Living With and Without Disability? A Cross-Sectional Study. Clin J Sport Med January 17, 2017

doi: 10.1097/JSM.000000000000040. Accessed Feb. 25, 2017

(17) Wessels, KK. Concussion assessment in wheelchair users: Quantifying seated postural control. University of Illinois at Urbana-Champaign, ProQuest Dissertations Publishing, 2013. 3632369

(18) West L, Griffin S, Weiler R, Ahmed o. Management of concussion in sport: a different ball game? Br J Sports Med Dec 2016, bjsports-2016-096767; DOI: 10.1136/bjsports-2016-096767. Accessed February 25, 2017.

(19) Finch C. A new injury framework for research leading to sports injury prevention. J Sci Med Sport 2006; 9: 3-9

(20) Baker SP (1973). "Injury Control". In Preventive medicine and public health. Rosenau MJ, Maxcy KF, \& Sartwell PE. New York: Appleton-Century-Crofts. [10th ed.]

(21) Bose D, Crandall JR. Influence of active muscle contribution on the injury response of restrained car occupants. Ann Adv Automot Med Assoc Adv Automot 
Med Annu Sci Conf 2008;52:61-

72.http://www.ncbi.nlm.nih.gov/pubmed/19026223 (accessed 4 Dec2017).

(22) Kajta Z, Karren J, Subic A. Experimental investigation into the suitability of smart polymers as an impact-absorbing material for an improved rugby headgear. International Conference on Mechanics, Materials, Mechanical Engineering and Chemical Engineeering (MMMCE 2015), 2015. http://www.inase.org/library/2015/books/MMMCE.pdf (accessed Dec 4, 2017) (23) West LR, Griffin S, Weiler R, Ahmed O. Management of concussion in disability sport: A different ball game? Br J Sports Med 2017 (51); 14: 1050-1051 (24) Knapp A. Five Leadership Lessons From James T. Kirk. Forbes March 5, 2012. Accessed December 2, 2017

Table 1: Para sports Summer and Winter with 'best estimate' of concussion risk based upon impairment type, speed, collision potential, protective wear and risk rating: 1 (low) to 5 (high) Abbreviations: $\mathrm{SCI}=$ spinal cord injury, $\mathrm{CP}=$ cerebral palsy, $\mathrm{VI}=$ visual impairment

\begin{tabular}{|l|l|l|l|l|l|}
\hline Summer Sports & $\underline{\text { Impairment }}$ & $\underline{\text { Collision }}$ & Impact Speed & Head Protection & Risk Rating \\
& & $\underline{\text { Potential }}$ & & & \\
\hline
\end{tabular}




\begin{tabular}{|c|c|c|c|c|c|}
\hline Archery & Multiple & V Low & V Low & No & 1 \\
\hline Boccia & $\mathrm{CP}$ & V Low & V Low & No & 1 \\
\hline Cycling Road & Handcycle & Moderate & High & Yes & 5 \\
\hline Cycling Road & Trike & Moderate & Mod-High & Yes & 3 \\
\hline Cycling Road & Bike & Moderate & High & Yes & 5 \\
\hline Cycling Track & Multiple & Moderate & Moderate & Yes & 3 \\
\hline Equestrian & Multiple & Low & Moderate & Yes & 2 \\
\hline Football 5-a-side & $\mathrm{VI}$ & High & Low & No & 4 \\
\hline Football 7-a-side & $\mathrm{CP}$ & Moderate & Low-Moderate & No & 2 \\
\hline Goalball & $\mathrm{VI}$ & Moderate & Moderate & No & 3 \\
\hline Judo & $\mathrm{VI}$ & Moderate & Moderate & No & 2 \\
\hline Para athletics Field & Wheelchair & Low & V Low & No & 1 \\
\hline Para athletics Field & Amputee & Low & Moderate & No & 2 \\
\hline Para athletics Field & $\mathrm{VI}$ & Low & Moderate & No & 2 \\
\hline Para athletics Field & $\mathrm{CP}$ & Low & Moderate & No & 2 \\
\hline Para athletics Track & Wheelchair & Moderate & Moderate & Yes & 3 \\
\hline Para athletics Track & Amputee & Low & Moderate & No & 1 \\
\hline Para athletics Track & $\mathrm{VI}$ & Low & Moderate & No & 1 \\
\hline Para athletics Track & $\mathrm{CP}$ & Low & Moderate & No & 1 \\
\hline Para canoe & Multiple & Low & Low & No & 2 \\
\hline Para Powerlifting & Multiple & V Low & V Low & No & 1 \\
\hline Para swimming & Multiple & Low & Low & No & 2 \\
\hline Para-Triathlon - Bike & Multiple & Moderate & High & Yes & 4 \\
\hline Para-Triathlon - Run & Multiple & Low & Low & No & 2 \\
\hline $\begin{array}{l}\text { Para-Triathlon - } \\
\text { Swim }\end{array}$ & Multiple & Low & Low & No & 2 \\
\hline
\end{tabular}




\begin{tabular}{|c|c|c|c|c|c|}
\hline Rowing & Multiple & V Low & Low & No & 2 \\
\hline Sailing & Multiple & Moderate & Moderate & No & 3 \\
\hline Shooting Para sport & Multiple & V Low & V Low & No & 1 \\
\hline Sitting Volleyball & Multiple & Low & Low & No & 2 \\
\hline Table Tennis & Multiple & Low & Low & No & 1 \\
\hline $\begin{array}{l}\text { Wheelchair } \\
\text { Basketball }\end{array}$ & Multiple & Low & Low & No & 2 \\
\hline Wheelchair Fencing & $\begin{array}{l}\text { T2 - T10, } \\
\text { Below }\end{array}$ & Low & Low & Yes & 2 \\
\hline Wheelchair Rugby & $\mathrm{SCl}$ & High & Low & No & 3 \\
\hline Wheelchair Tennis & Multiple & Low & Low & No & 2 \\
\hline Winter Sports & Impairment & $\begin{array}{l}\text { Collision } \\
\text { Potential }\end{array}$ & Impact Speed & Head Protection & Risk Rating \\
\hline Para alpine Downhill & Sitski & V High & V High & Yes & 5 \\
\hline Para alpine Downhill & $\mathrm{VI}$ & V High & V High & Yes & 5 \\
\hline Para alpine Downhill & Standing & V High & V High & Yes & 5 \\
\hline Para alpine Other & Sitski & High & High & Yes & 4 \\
\hline Para alpine Other & VI & High & High & Yes & 4 \\
\hline Para alpine Other & Standing & High & High & Yes & 4 \\
\hline Para alpine Slalom & Sitski & Moderate & High & Yes & 3 \\
\hline Para alpine Slalom & $\mathrm{VI}$ & Moderate & High & Yes & 3 \\
\hline Para alpine Slalom & Standing & Moderate & High & Yes & 4 \\
\hline $\begin{array}{l}\text { Para cross-country } \\
\text { skiing/Biathlon }\end{array}$ & Sit ski & Low & Low & No & 2 \\
\hline $\begin{array}{l}\text { Para cross-country } \\
\text { skiing/Biathlon }\end{array}$ & VI & Low & Low & No & 2 \\
\hline
\end{tabular}




\begin{tabular}{|c|c|c|c|c|c|}
\hline $\begin{array}{l}\text { Para cross-country } \\
\text { skiing/Biathlon }\end{array}$ & Standing & Low & Low & No & 4 \\
\hline Para ice hockey & Multiple & High & Moderate & Yes & 1 \\
\hline Para snowboard & Standing & High & Moderate & Yes & 2 \\
\hline Wheelchair Curling & Multiple & V Low & V Low & No & 1 \\
\hline
\end{tabular}

Table 2. Potential challenges to the use of sections of the SCAT5 in the Para athlete

\begin{tabular}{|l|l|}
\hline SCAT5 SECTION & POTENTIAL CHALLENGES \\
& \\
\hline
\end{tabular}




\begin{tabular}{|c|c|}
\hline 1. Immediate or on-field assessment & \\
\hline $\begin{array}{l}\text { - Red flags } \\
\text { - Observable signs } \\
\text { - Maddocks questions } \\
\text { - Glasgow Coma Scale } \\
\text { - Cervical spine assessment }\end{array}$ & $\begin{array}{l}\text { Motor/sensation impairment, visual impairment } \\
\text { Balance/coordination impairment } \\
\text { Balance difficulty, motor incoordination } \\
\text { Hearing impairment, cognitive impairment, speech } \\
\text { impairment } \\
\text { Hearing impairment, visual impairment, motor } \\
\text { impairment, speech impairment } \\
\text { Neck movement impairment }\end{array}$ \\
\hline 2. Symptom evaluation & $\begin{array}{l}\text { More likely to have pre-existing symptoms; } \\
\text { different baseline }\end{array}$ \\
\hline 3. Cognitive screening & $\begin{array}{l}\text { Cognitive impairment, learning disability, speech } \\
\text { impairment }\end{array}$ \\
\hline
\end{tabular}




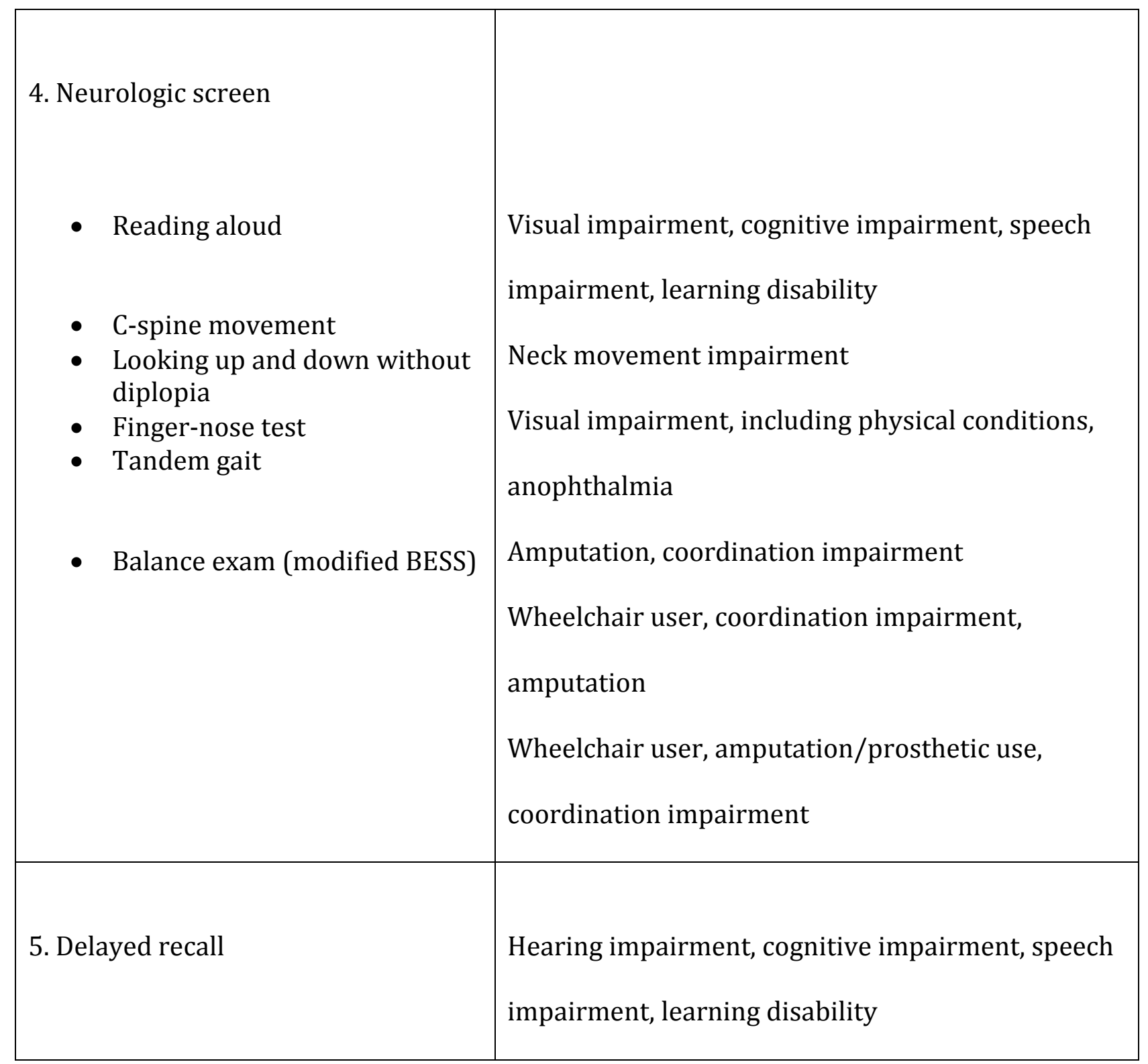




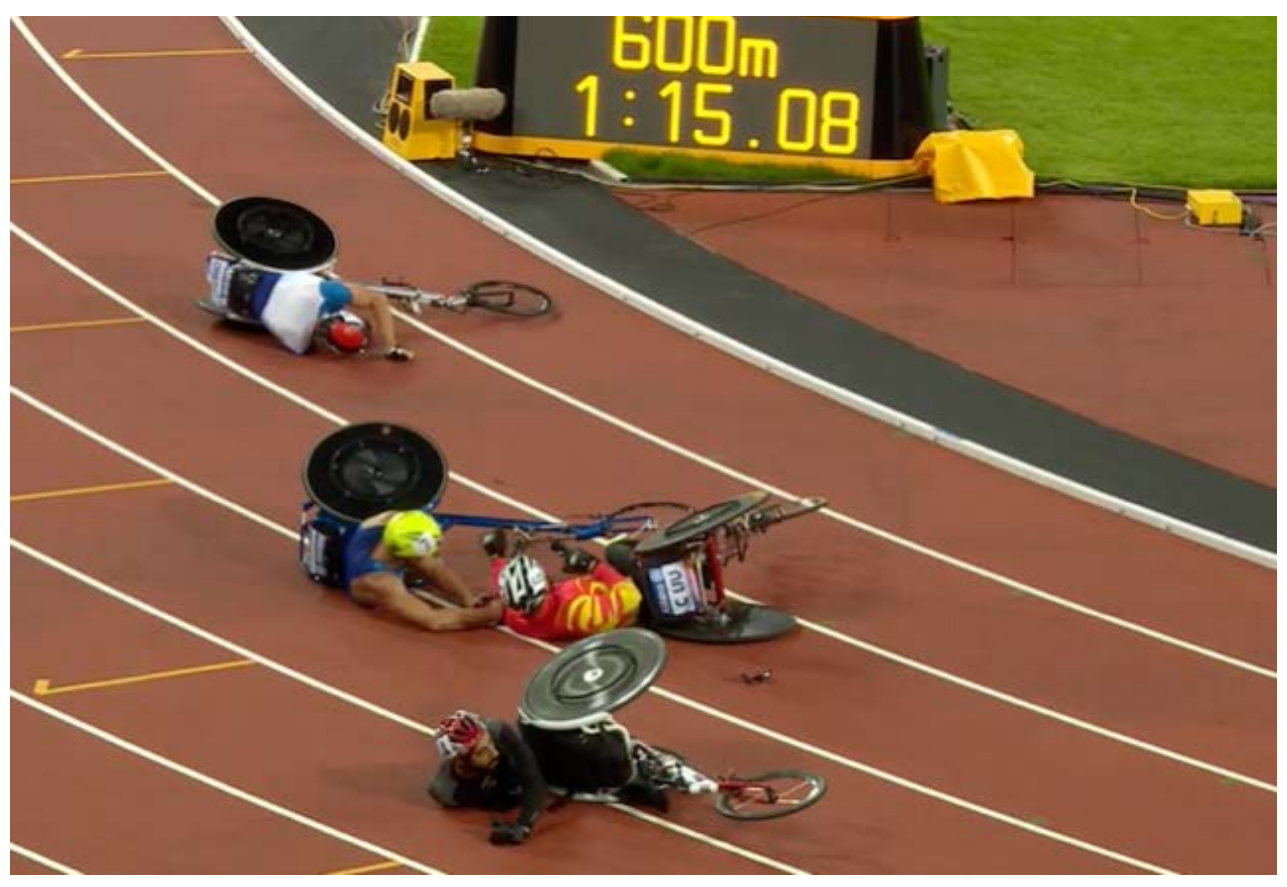

FIG 1. Wheelchair racing crash

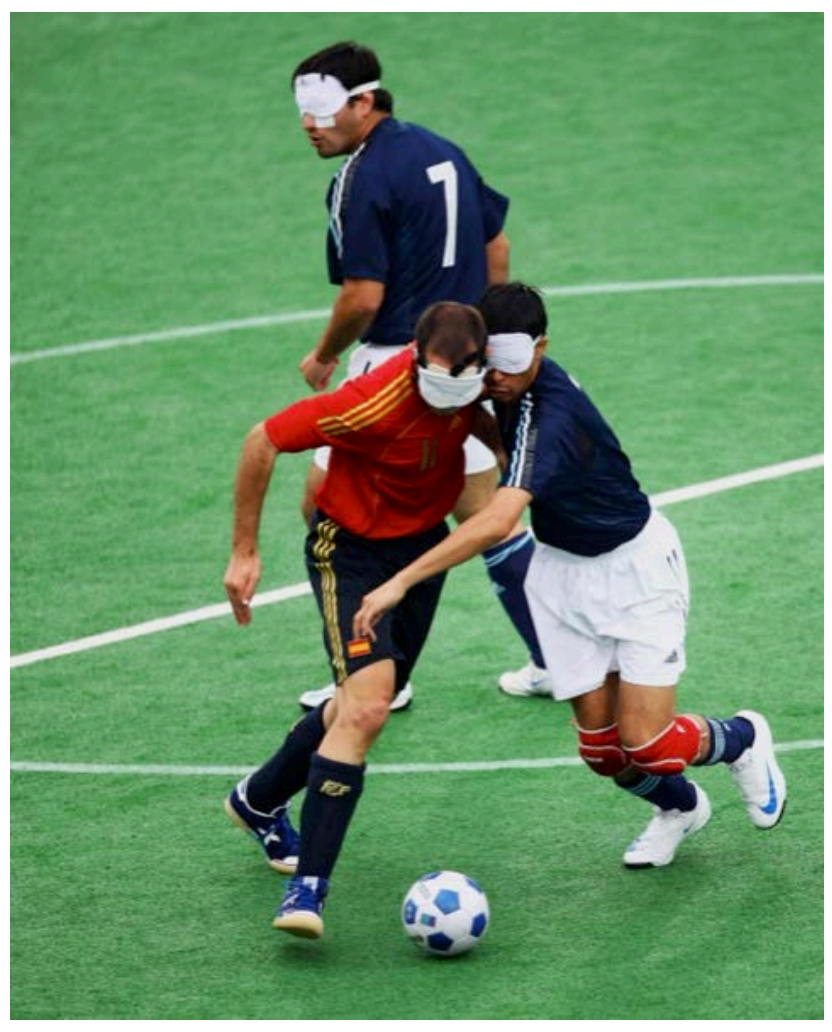

FIG 2. Football 5 action 


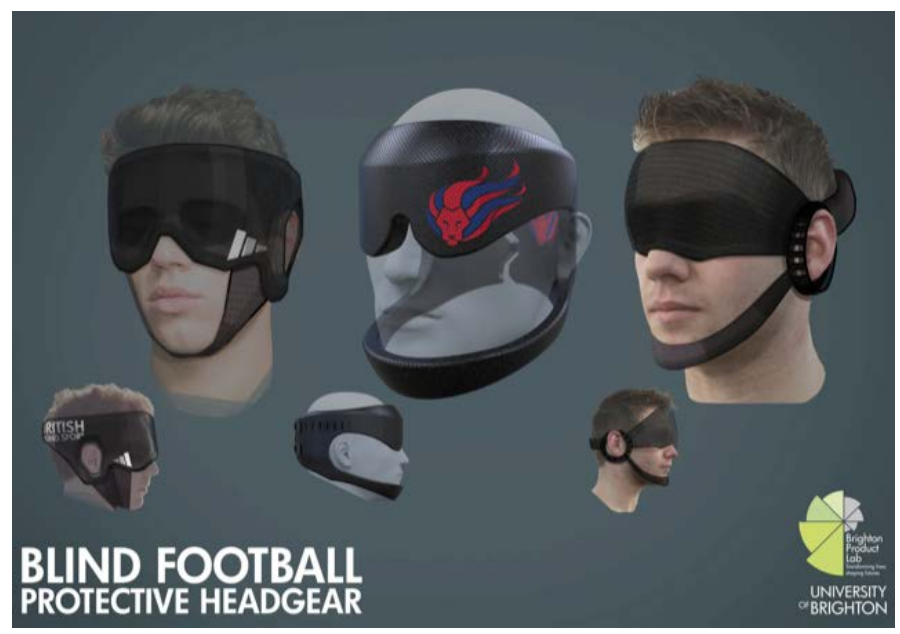

FIG 3. Proposed Football 5 eyeshade/headgear design 